\title{
Electric Stress Analysis of 132 kV Composite Long Rod Insulator
}

\author{
Kavyashree C. $\mathbf{M}^{1}$, Shilpa S. $\mathbf{K}^{2}$ \\ ${ }^{1,2}$ Department of E\&E Engineering, Bapuji Institute of Engineering and Technology, Shamanur Road, Davangere, Karanataka 577004,
} India

\begin{abstract}
Polymer insulators which are being used gradually more for open-air applications have improved characteristics than porcelain and glass types. However, since polymer insulators are made of organic materials, deterioration through aging is unavoidable. The E- field distribution on the surface of and within the composite insulators is a function of abundant parameters together with applied voltage, insulator design, tower configuration, hardware design, corona ring etc,. This paper deals with the two-dimensional electric field simulation of $132 \mathrm{kV}$ composite long rod insulator worn in high voltage distribution and transmission systems. The computer simulations are carried out by using commercially available software package ANSYS. The potential and electric filed consequences obtained for the actual insulator profile with and without corona ring are discussed and presented.
\end{abstract}

Keywords: Composite insulator, electric field distribution, Corona ring, optimization.

\section{Introduction}

Composite insulators offer several advantages over porcelain insulators. They have good performance under contaminated conditions, high mechanical strength, less maintenance necessity, light weight and reduced maintenance costs [1].For optimal design of line insulators, it is important to calculate the electric field and potential distribution the length of the insulator surface. High levels of electric field are responsible for audible sound, electromagnetic contamination, partial discharge and premature aging of insulation. Knowledge of the electric field along the exterior surface is an essential requirement for the reliable performance of electrical system. Electric field distribution is affected by a variety of factors like the geometry of the insulator, the geometry of the attachment hardware, value of energized line voltage and presence of nearby phases [3].

The potential and electric field distribution on the insulator surface is extremely rough. The joint of rod, silicon rubber and end fitting has the maximum electric field strength while the first shed gets the maximum distributed voltage. Sealing points have the minimum electric field strength and a low valued electric stress can easily erodes it and causes to occur flashovers and mechanical failures. According to the standards corona phenomenon happens when the electric field on the surface of the composite insulator and end fitting exceeds the allowed value, which can affect the electromagnetic environment of power transmission lines and insulation material properties [3].The electric field distribution on composite insulators affects both long term and short term performance. Prolonged exposure to corona activity, despite of the primary cause, degrades insulators and shortens their life time. In order to design and pertain composite insulators effectively, a basic understanding of the E-field distribution and its outcome on the insulator performance is needed [5].

Manufacturers do not recommend the application of corona ring for insulators below $220 \mathrm{kV}$. In India, some utilities are experiencing failures of $132 \mathrm{kV}$ composite long rod insulators. In the present work an attempt has been made to investigate whether these failures are attributes of high electric stresses occurring close to end fittings and critical areas like triple junction.. The electric field distribution composite long rod insulators under dry and clean conditions with and without corona ring have been presented. A three dimensional modelling of the composite insulator and finite element discretization of the model were done by using commercially available CATIA and HYPERMESH software. The simulations were also done.

\section{Computation Methodology}

The insulator proportions are obtained from manufacturer's catalogue. The dry dimensions of the insulators for different voltage ratings are listed in table 1 . The present study modeled single insulators with and without corona rings.

Table1: The size of 132kVComposite Insulator \begin{tabular}{|l|l|l|}
\hline Voltage rating & Dry-arc distance & Leakage distance \\
\hline
\end{tabular} \begin{tabular}{|l|l|l|}
\hline $132 \mathrm{kV}$ & $1090 \mathrm{~mm}$ & $4600 \mathrm{~mm}$ \\
\hline
\end{tabular}

\subsection{Modeling of the insulator using CATIA software}

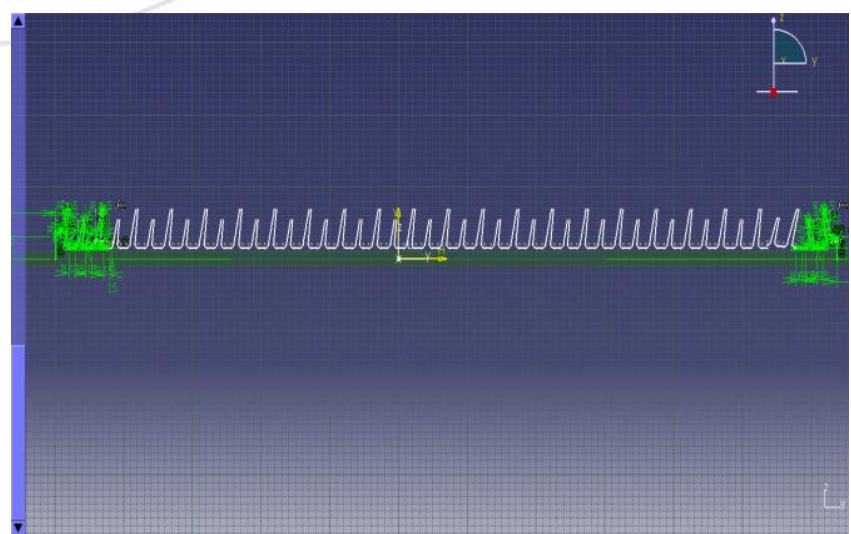




\section{International Journal of Science and Research (IJSR) \\ ISSN (Online): 2319-7064}

Index Copernicus Value (2013): 6.14 | Impact Factor (2015): 6.391

\section{$2.12 \mathrm{D}$ view of $132 \mathrm{kV}$ composite long rod insualtor}

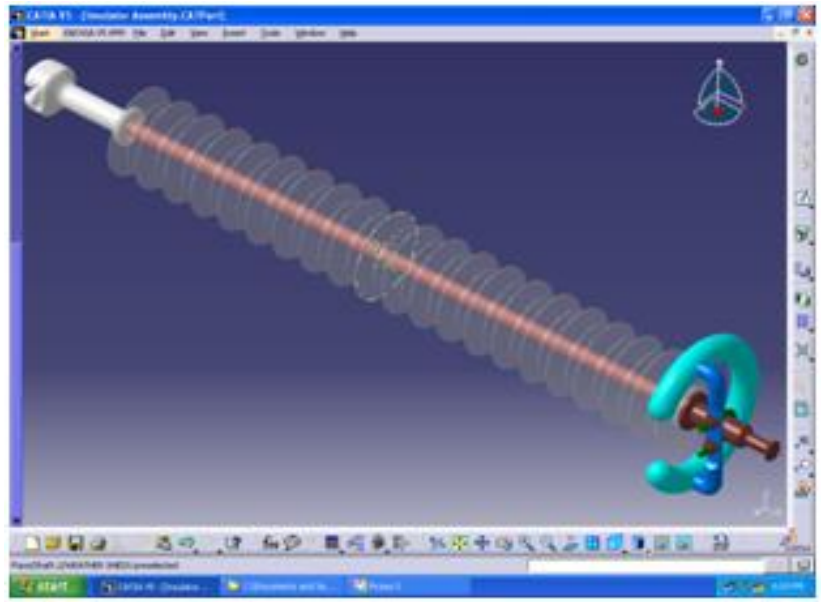

Figure 2.2: $3 \mathrm{D}$ view of the $132 \mathrm{kV}$ insulator model with Corona Ring

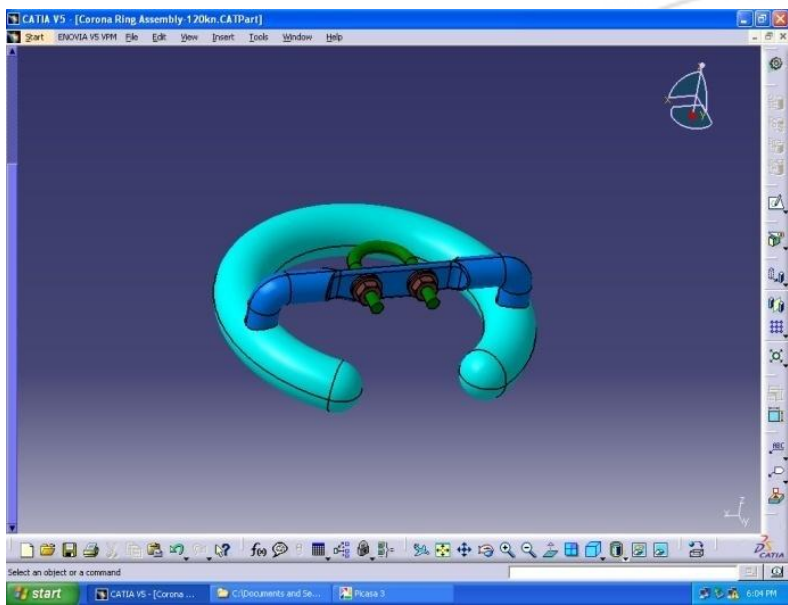

Figure 2.3: The 3D view of Corona Ring for $132 \mathrm{kV}$ insulator

\subsection{Discretization using Hypermesh software}

Initially, the 3D model is imported to Hypermesh. Here, the model is cut into half part and then quarter part. The quarter part of the insulator is meshed using Hypermesh software. In meshing, 2D spline and automesh is selected to get exact meshed model. After that, the properties of meshing and electrical properties of tria, quads are to begiven so that the direction of the meshes should be in one direction and the analysis should be good. After applying all the above properties and the meshing, the model is as shown below in fig 2.4

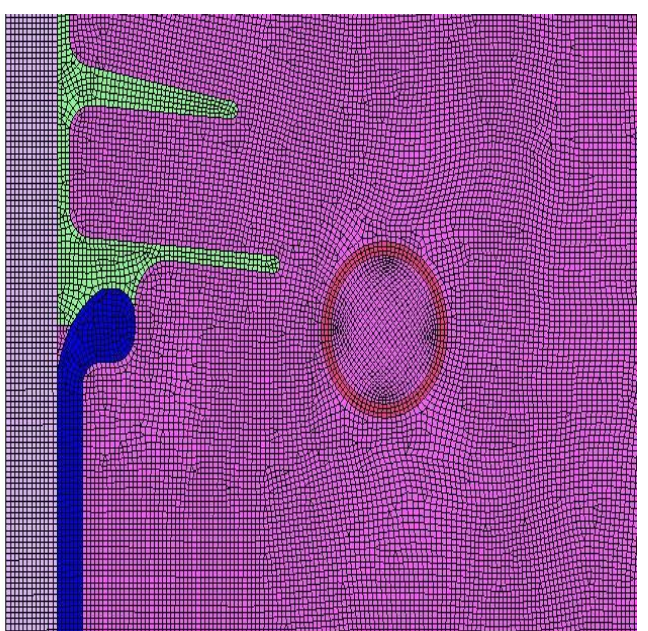

Figure 2.4: The meshed model of specimen insulator with corona ring

After obtaining the meshed models from Hypermesh the files are to be imported into ANSYS.

\section{Results and Discussions}

\subsection{Electric field distribution}

As mentioned earlier the profile of the insulator is obtained after transferring the actual data of the insulators to the computer. Subsequently the model is meshed and the electric field plots are obtained for the insulators. The fig.3.3 shows the electric field distribution of the composite insulator model under consideration. There are three major regions useful when considering the E-field distribution of composite insulators. For the purpose of analysis the following four regions were considered. They are:

1) On the surface of and in the air adjoining the polymer weather shed surface and nearby the end fitting.

2) Inside the fiber glass rod in addition to at the interfaces linking these materials and the metal end fitting.

3) On the surface of and in the air surrounding the metallic end fittings attached to corona rings.

4) Triple junction point.

The E-field at the regions under consideration are tabulated in table $3.1 \& 3.2$.

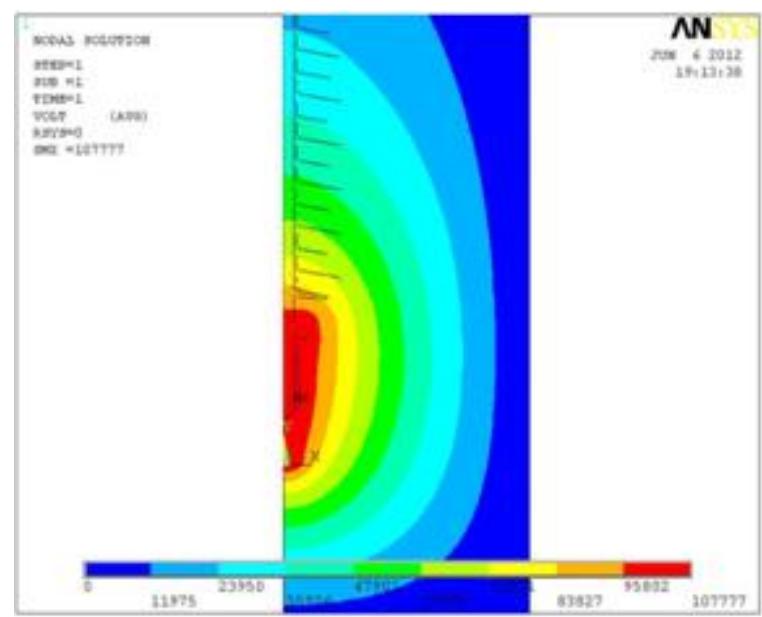

Figure 3.1: Electric potential plot without corona ring 


\section{International Journal of Science and Research (IJSR) \\ ISSN (Online): 2319-7064}

Index Copernicus Value (2013): 6.14 | Impact Factor (2015): 6.391

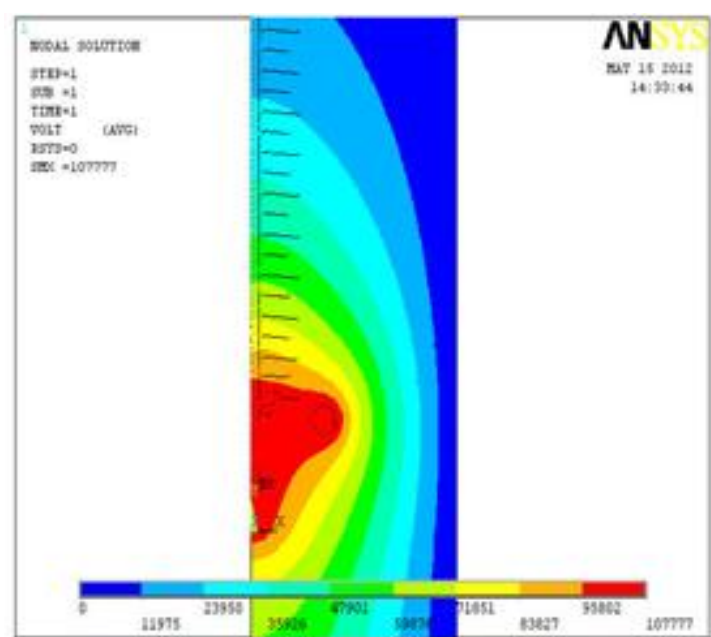

Figure 3.2: Electric potential plot with corona ring

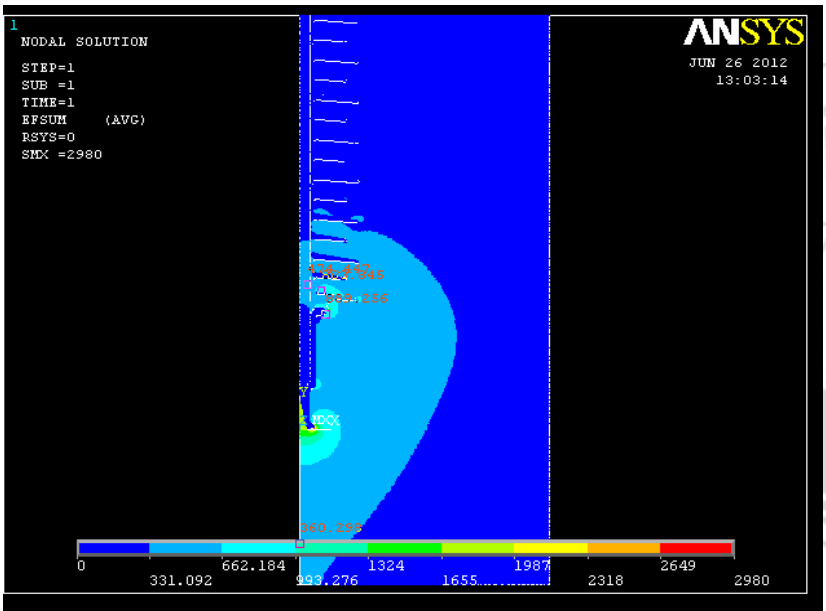

Figure 3.3: A plot showing Electric Field distribution of $132 \mathrm{kV}$ composite insulator without corona ring

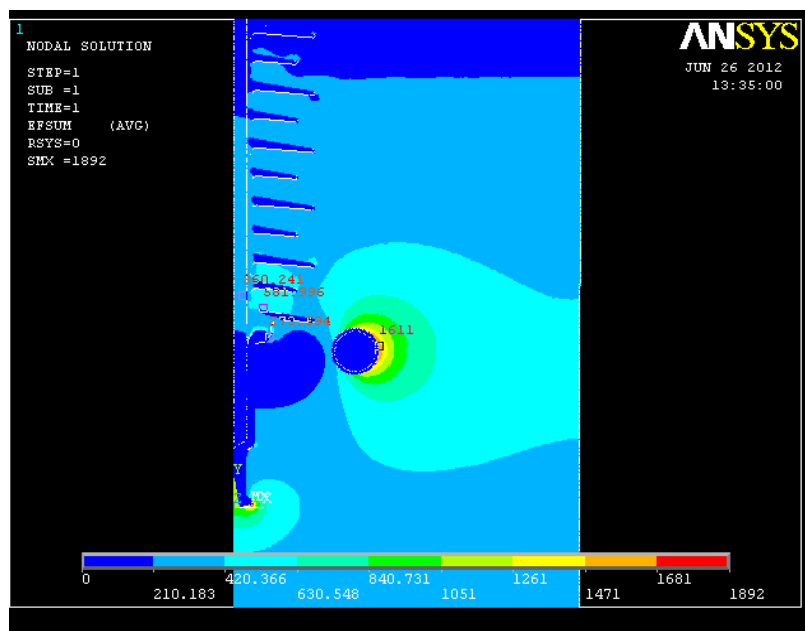

Figure 3.4: A plot showing Electric Field distribution of $132 \mathrm{kV}$ composite insulator with corona ring

In the present work to study the influence of important design parameters of coronaring on the maximum E-field distribution, the ring is fixed at the highly stressed live end. The variations in the size of corona ring were made by changing the outer diameter and cross sectional diameter. The analysis using ANSYS were done to calculate and plot the E-field distribution with corona ring with the following dimensions.

\section{For 132kV}

Case 1: Outer Diameter: $220 \mathrm{~mm}$ with Cross sectional diameters: 30,40 and $50 \mathrm{~mm}$

Case 2: Outer Diameter: $240 \mathrm{~mm}$ with Cross sectional diameters: 30,40 and $50 \mathrm{~mm}$

Case 3: Outer Diameter: $250 \mathrm{~mm}$ with Cross sectional diameters: 30,40 and $50 \mathrm{~mm}$

Table 3.1: Maximum E-field in $\mathrm{kV} / \mathrm{mm}$ on different locations of $132 \mathrm{kV}$ composite insulator

\begin{tabular}{|c|c|c|c|c|c|c|}
\hline $\begin{array}{c}\text { Outer } \\
\text { diameter of } \\
\text { the ring in } \mathrm{mm}\end{array}$ & $\begin{array}{c}\text { Cross section } \\
\text { diameter in } \\
\mathrm{mm}\end{array}$ & $\begin{array}{l}\text { Max E-field on } \\
\text { End fitting in } \\
\mathrm{kV} / \mathrm{mm}\end{array}$ & $\begin{array}{l}\text { Max E-field On } \\
\text { Ring in } \mathrm{kV} / \mathrm{mm}\end{array}$ & $\begin{array}{c}\text { Max E-field around } \\
\text { first Shed in in } \\
\mathrm{kV} / \mathrm{mm}\end{array}$ & $\begin{array}{c}\text { Max E-field on } \\
\text { FRP Rod kV/mm }\end{array}$ & $\begin{array}{l}\text { Max E-field on } \\
\text { Triple Junction } \\
\text { Point in } \mathrm{kV} / \mathrm{mm}\end{array}$ \\
\hline 220 & $\begin{array}{l}30 \\
40 \\
50 \\
\end{array}$ & $\begin{array}{l}1.972 \\
1.946 \\
1.923\end{array}$ & $\begin{array}{r}1.715 \\
1.519 \\
1.388 \\
\end{array}$ & $\begin{array}{l}0.629 \\
0.606 \\
0.581\end{array}$ & $\begin{array}{l}0.378 \\
0.367 \\
0.360\end{array}$ & $\begin{array}{l}0.329 \\
0.237 \\
0.211\end{array}$ \\
\hline 240 & $\begin{array}{l}30 \\
40 \\
50\end{array}$ & $\begin{array}{l}1.937 \\
1.909 \\
1.883\end{array}$ & \begin{tabular}{|l|}
1.787 \\
1.599 \\
1.459 \\
\end{tabular} & $\begin{array}{l}0.623 \\
0.596 \\
0.570\end{array}$ & $\begin{array}{l}0.374 \\
0.361 \\
0.341\end{array}$ & $\begin{array}{l}0.369 \\
0.275 \\
0.200\end{array}$ \\
\hline 250 & $\begin{array}{l}30 \\
40 \\
50\end{array}$ & $\begin{array}{l}1.922 \\
1.892 \\
2.266\end{array}$ & $\begin{array}{l}1.835 \\
1.611 \\
1.493\end{array}$ & $\begin{array}{l}0.610 \\
0.581 \\
0.573\end{array}$ & $\begin{array}{l}0.370 \\
0.360 \\
0.351\end{array}$ & $\begin{array}{l}0.385 \\
0.273 \\
0.209\end{array}$ \\
\hline
\end{tabular}

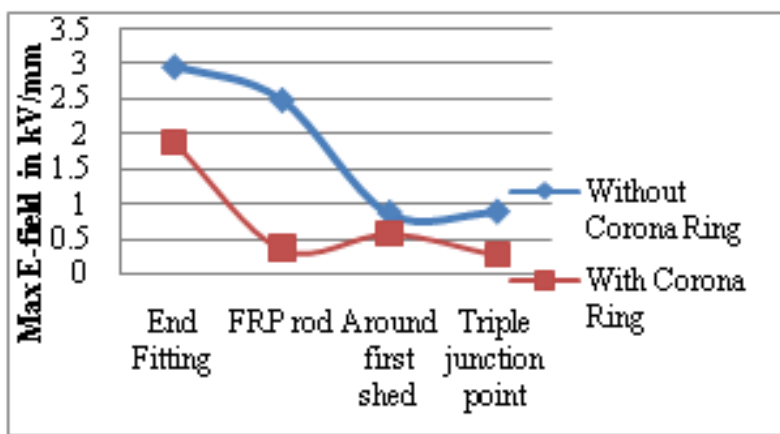

Figure 3.5: Variation of Maximum E-field on 132kV insulator with and without ring
It was observed from the table 3.1 and fig.3.4 that the maximum E-field at all regions of interest were below the critical E-field values. It was also observed that the maximum E-field along the length of the insulator was shifted to the region of surface of air near the first shed, which is away from the more stressed metal end fitting. This shift improves the performance of the insulator assembly reducing the stress at the most vulnerable region for initiation of partial arcs. 


\section{International Journal of Science and Research (IJSR) \\ ISSN (Online): 2319-7064}

Index Copernicus Value (2013): 6.14 | Impact Factor (2015): 6.391

\section{Conclusions}

In this study, the electric field distributions in the vicinity of $132 \mathrm{kv}$ composite insulator under dry and clean conditions have been presented. FEM based electric field analysis program ANSYS has been used for the calculation of electric field. The following conclusions can be drawn from the proposed work.

1) The distribution of the potential for all the cases are found to be same, the diameter of the corona ring does not change the potential distribution.

2) The electric stress obtained at the end fitting, on triple junction point, around first shed without corona ring are higher and slightly more than the stress limits recommended by EPRI.

3) By the application of corona ring, the magnitude of the maximum E-field at all the regions of interest can be brought down below the respective critical E-field values.

4) Application of corona ring shifts the region of occurrence of maximum E- field away from the most vulnerable region for starting and initiation of partial arcs.

From the above simulations it can be concluded that a corona ring of outer diameter $240 \mathrm{~mm}$ and cross section diameter of $50 \mathrm{~mm}$ is the appropriate for $132 \mathrm{kV}$ composite long rod insulator.

\section{References}

[1] Subba Reddy, Anuja Kumar, Shashikala A, Ravishankar K.V, "Electric Field Modelling of Composite High Voltage Insulators", India Conference (INDICON),2009 annual IEEE.

[2] Masoud Jowkar, Ahmad Gholami, "Corona Ring Designation for $400 \mathrm{kV}$ AC Transmission Line with Composite Insulators by FEM", International Power SystemConference, 2011.

[3] Andrew J. Phillips, John Kuffel, Anthony Baker, Jeffery Burnham, AnthonyCarreira, Edward Cherney, Anthony Gillepsie, Thomas Grisham, RobertGermingnani, Robert Hill, "Electric Fields on AC Composite Transmission Line Insulators", IEEE transactions on power delivery, VOL.23, NO.2, APRIL 2008.

[4] W.Sima, F.P Epsino Cortes, Edward.A "Optimization of Corona Ring Designfor long rod insulators Using FEM Based Computational Analysis", ConferenceRecord of the 2004 IEEE International Symporium.

[5] T. Doshi, R. S. Gorur, "Electric Field Computation of Composite Line Insulatorsup to $1200 \mathrm{kV}$ AC", IEEE Transactions on Dielectrics and Electrical Insulation Vol.18, No. 3; June 2011.

[6] Bo Zhang, Shejiao Han, Jinliang He, Rong Zeng, and Puxuan Zhu, "NumericalAnalysis of Electric-Field Distribution Around Composite Insulator and Head ofTransmission Tower", IEEE transactions on power delivery, VOL. 21, NO. 2, APRIL2006.

[7] Eleperuma, T.K. Saha, T.Gillespie, "Electric Field Modelling of Non-CeramicHigh Voltage Insulators", University of Queenland, Australia.

[8] U. Schumann, F. Barcikowski, M. Schreiber, H. C. Karner "FEM Calculationand Measurement of the Electrical Field Distribution of HV Composite Insulator
Arrangements", 39th CIGRE session, Paris, France, Aug 2002.

[9] B. Vancia, T.K. Saha, T.Gillespie, "Electric Field Modelling of Non-Ceramic High Voltage Insulators".

[10] Weiguo Que and Stephen A. Sebo, "Electric Field and Voltage Distribution along Non-Ceramic Insulators" Stephen A.Sebo, Department of Electrical Engineering, The Ohio State University, Columbus.

[11] Tiebin Zhao, and Michael G. Comber, "Calculation of Electric Field and Potential Distribution along Nonceramic Insulators considering the effects of Conductors and Transmission Towers" IEEE Transactions On Power Delivery, Vol.15, No. 1, January 2000.

\section{References}

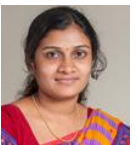

Kavyashree $\mathbf{C}$ M received her $\mathrm{BE}$ degree in the department of EEE, from Kuvempu University, in 2009, M.Tech (Power system and Power Electronics) from Davangere University in 2012, Karnataka, India. She is currently working as an Assistant Professor in the Dept. of EEE, BIET, Davangere, Karnataka, India.

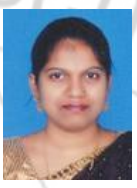

Shilpa S.K received her BE degree in the department of EEE, from Kuvempu University, in 2008, M.Tech (Power system and Power Electronics) from Kuvempu University in 2010, Karnataka, India. She is currently working as an Assistant Professor in the Dept. of EEE, BIET, Davangere, Karnataka, India. 